\title{
Perceptions of Prescribers towards Electronic Prescription: A Pre-Implementation Evaluation
}

\author{
Dhanya S Palappallil ${ }^{1 *}$, Carol Pinheiro ${ }^{2}$ \\ ${ }^{1}$ Assistant Professor, Department of Pharmacology, Govt Medical College, Kottayam, Kerala, INDIA. \\ ${ }^{2}$ Assistant Professor, Department of Community Medicine, Govt TDMC, Alappuzha, Kerala, INDIA.
}

\begin{abstract}
Objective: Electronic (e) prescribing is computerised prescribing. The Government of Kerala has started the e-health initiative. The objective of this study was to obtain the perceptions of prescribing doctors on e-prescription before its implementation. Method: This was a questionnaire based cross sectional study conducted for a period of six months in a Government tertiary care teaching hospital of Kerala. The prescribing doctors of the institution formed the sample population. The response to the structured questionnaire was measured on Likert scale. Data were analysed using SPSS 16. Domain scores of perceived usefulness, ease of use and fitness to the Institution were calculated by averaging the response. Chi square test was done to find the association of score of each domain with independent variables. Results: Two hundred and fifty seven prescribing doctors of age range 22-60 years participated of which $49 \%$ were females and $51 \%$ males. Response rate was $73 \%$ (257/350). Although $70.5 \%$ have heard of e-prescriptions only $14 \%$ participants had hands on exposure. The mean perceived usefulness, perceived ease of use and fitness were $3.5 \pm 0.47,3.35 \pm 0.49$ and $2.95 \pm 0.44$. Conclusion: Dislike for paper
\end{abstract}

prescriptions was the single most important factor associated with perceived usefulness, perceived ease of use and perceived fitness of e-prescription in the institution. Information technology training and infrastructure development should go hand in hand with implementation of e-prescribing

Key words: Electronic prescribing, Electronic prescription, Medication error, Health Information Technology.

Key Messages: For successful implementation of electronic prescriptions, training and technologically developed settings is a must. Educating the prescribers on preventable medication errors associated with paper prescriptions can lead to the acceptance of e-prescribing.

Correspondence

Dhanya S Palappallil, Assistant Professor, Department of Pharmacology, Govt Medical College, Kottayam, Kerala, INDIA.

Phone: 9747263211

Email: drspdhanya@gmail.com

DOI: 10.5530/iyp.2018.10.69

\section{INTRODUCTION}

Prescription is a written order by the doctor to the pharmacist. It has the status of a legal document. Re-dispensing with repeated use of same prescription is illegal. The common problems faced with handwritten prescriptions are poor legibility, incomplete writing or insufficient information, use of non-standard abbreviation, unintended omissions, failure to stop a drug timely, dose errors, dosage form errors and rarely inaccuracy in writing. ${ }^{1}$

Electronic (e) prescribing is the evolution of traditional methods to a technological advancement. It is an integral component of the health information technology (IT) system, an inter-operational platform, bridging communication gaps among doctors, patients, nurses and pharmacists. It has the potential to enhance the safety of pharmacological treatment by reducing the morbidity associated with medication errors by eliminating illegible hand writing, providing alerts on drug-drug interaction and drug allergy. ${ }^{2}$ By offering access to medication history, including prescriptions issued by other prescribers it helps to identify "doctor shoppers". The time spend handling the prescription renewal requests are considerably reduced. ${ }^{3}$ Electronic prescribing for controlled substances curbs the abuse and diversion of prescription drugs. This is by substantially reducing prescription fraud associated with paper prescriptions like falsifying prescriptions, prescription pad theft and forgery. ${ }^{4}$

Errors with e-prescribing is seen to be on the rise soon after its implementation. ${ }^{5}$ It may be attributed to technology factors like poor user interface design like auto-populate features and dropdown menus, end user factors like poor knowledge of the e-prescribing platform or inadvertently entering incorrect information and environmental factors such as lack of time or poor location of the computer. ${ }^{6}$ The effect of e-prescription on the pharmaceutical market is towards a negative side as physicians will prescribe the cheaper generic drugs as opposed to the expensive branded ones.

The Government of Kerala launched the e-health initiative in $2014 .^{7}$ The objective of this study was to obtain the perceptions of the prescribers on perceived usefulness, ease of use and fitness of e-prescribing system before its implementation. The positive predictors favouring its adoption in the institution were also studied.

\section{METHODS}

This was a cross sectional, questionnaire based study done amongst the prescribing doctors of a Government teaching hospital in Kerala. The study period was six months from July to December 2016. Sample size was computed as 257 at $95 \%$ confidence level allowing $5 \%$ margin of error. Stratified sampling was done and 92 Permanent doctors, 67 Residents and 98 Interns formed the sample.

The study was initiated after getting the Institutional Review Board and Ethics Committee Approval (EC/13/2015 dated 15/12/2015 of the institution). Practising doctors were invited to participate in the study by distributing a structured questionnaire. Two reminders encouraging the completion of instrument were given personally and mobile messaging or email. Three hundred and fifty questionnaires were distributed to achieve the target sample size. 
The questionnaire was partially adopted from Agency for Healthcare Research and Quality. ${ }^{8}$ The instrument was modified based on previous survey instruments which assessed the extent of use of computers amongst health professionals, Roger's innovation diffusion theory, Davis's Technology Acceptance Model and Dixon's IT Adoption Model. ${ }^{9-12}$ The questionnaire consisted of 6 parts -Demography, Current prescribing activities, Computer Usage, Perceived usefulness, Perceived ease of use and Perceived fitness of e-prescriptions. The response was measured on Likert scale 1(Strongly disagree) to 5 (Strongly agree).

Statistical Analysis-The data were analysed using SPSS 16 for windows (SPSS Inc, Chicago, USA). Prior to conducting the analysis the internal consistency of instrument was assessed for reliability using Cronbach's coefficient alpha $(\geq 0.8)$. The response to each question was presumed to be the score of that question. The scores were reversed for negative questions and mean domain scores were calculated. Responses were dichotomized (1-3 as bad and 3.1-5 as good) for further analysis. Chi square test was done to find the association of score of each domain with independent variables. Using binary logistic regression model predictors of perceived usefulness, ease of use and fitness of e-prescribing in the institution were evaluated.

\section{RESULTS}

Three hundred and fifty questionnaires were distributed of which 257 were returned, response rate being 73\%. There were 126 females and 131 males with a mean age $31 \pm 8.59$ years (range $22-60$ ). About $24.1 \%$ (62) were from medical specialty, $37.7 \%$ (97) from surgical and the rest were interns who had prescribing experience of less than one year. Around $33.9 \%$ had prescribing experience of more than five years. More than fifty percent participants claimed that they had high volume load of patients. The current prescribing activities of the participants are summarized in Table 1. Even though $70 \%$ claimed their prescriptions to be legible and $60.7 \%$ liked paper prescriptions, only $40 \%$ were able to track the continuity of their prescription as shown in Table 1.

Around $70.8 \%$ had computer usage experience for more than 5 years, $23.7 \%$ for $1-5$ years and the rest less than one year. As shown in Table 2, $79 \%$ were comfortable with use of computers, and only $57.6 \%$ had selfassessed good knowledge of computers. Of the 70.5\% (181) who have heard of e-prescriptions only 14\% (37) had hands on exposure in generating it.

The mean perceived usefulness, ease of use and fitness were $3.5 \pm 0.47$, $3.35 \pm 0.49$ and $2.95 \pm 0.44$ respectively. As shown in Figure 1, majority of the participants thought that ability to send e-prescription will be good (65\%) and would lead to safer prescribing (63\%) with less medication errors. A vast majority liked getting notified when there was potential chance of drug-drug interactions (80.5\%), whether the patients received the prescribed medication from the pharmacies (67.3\%) and what other doctors prescribed for co-existing illness (73.2\%). Only $30.4 \%$ were afraid that their work would be controlled while sending e-prescriptions. Even though almost equal number of participants agreed and disagreed on the fact that storage of personal healthcare information in database would be unethical and would lead to data abuse, $79.4 \%$ agreed that this data could be used for research purpose. More than $50 \%$ of the participants disagreed to the statement that e-prescribing would decrease the economic burden of healthcare system.

As shown in Figure 2, about 45\% agreed that using e-prescription means faster or easier prescribing. Even though only $35.8 \%$ felt that it would affect the work flow around $60 \%$ opined that it would cause technical problems, require regular technical assistance, patients might think that doctors were referring to the internet for prescribing and unauthorized e-prescriptions might be send by hacking and logging into their user interface. Despite thinking that prescribing through software would be
Table 1: Current prescribing activities of the participants ( $n=257$ ).

\begin{tabular}{cccc}
\hline Variables & $\begin{array}{c}\text { Disagree } \\
(1+2) \%\end{array}$ & $\begin{array}{c}\text { Neutral } \\
(3) \%\end{array}$ & $\begin{array}{c}\text { Agree } \\
(4+5) \%\end{array}$ \\
\hline Have legible handwriting & 7.8 & 22.2 & 70.0 \\
Like paper prescription & 17.1 & 22.2 & 60.7 \\
Able to track continuity & 32.3 & 23.7 & 44.0 \\
Refill demand for lost prescription & 58.8 & 20.6 & 20.6 \\
Prescriptions were altered by patients & 56.8 & 23.3 & 19.8 \\
Prescription pads were stolen & 70.0 & 34.0 & 16.7 \\
Pharmacists called back to clear doubts & 38.9 & 31.9 & 29.2 \\
Incorrect drug was filled from & 54.1 & 21.8 & 20.6 \\
pharmacy & & & \\
\hline
\end{tabular}

Table 2: Current computer usage profile of the participants ( $n=257)$.

\begin{tabular}{cccc}
\hline Variables & $\begin{array}{c}\text { Disagree } \\
(1+2) \%\end{array}$ & $\begin{array}{c}\text { Neutral } \\
(3) \%\end{array}$ & $\begin{array}{c}\text { Agree } \\
(4+5) \%\end{array}$ \\
\hline $\begin{array}{c}\text { Comfort with computer use } \\
\text { Computer use for personal/professional } \\
\text { purposes }\end{array}$ & 6.2 & 14 & 79.8 \\
$\quad \begin{array}{c}\text { Use computer at home } \\
\text { Use computer in hospital }\end{array}$ & 13.2 & 15.2 & 71.6 \\
Good knowledge on computer & 41.6 & 28.8 & 29.6 \\
\hline
\end{tabular}

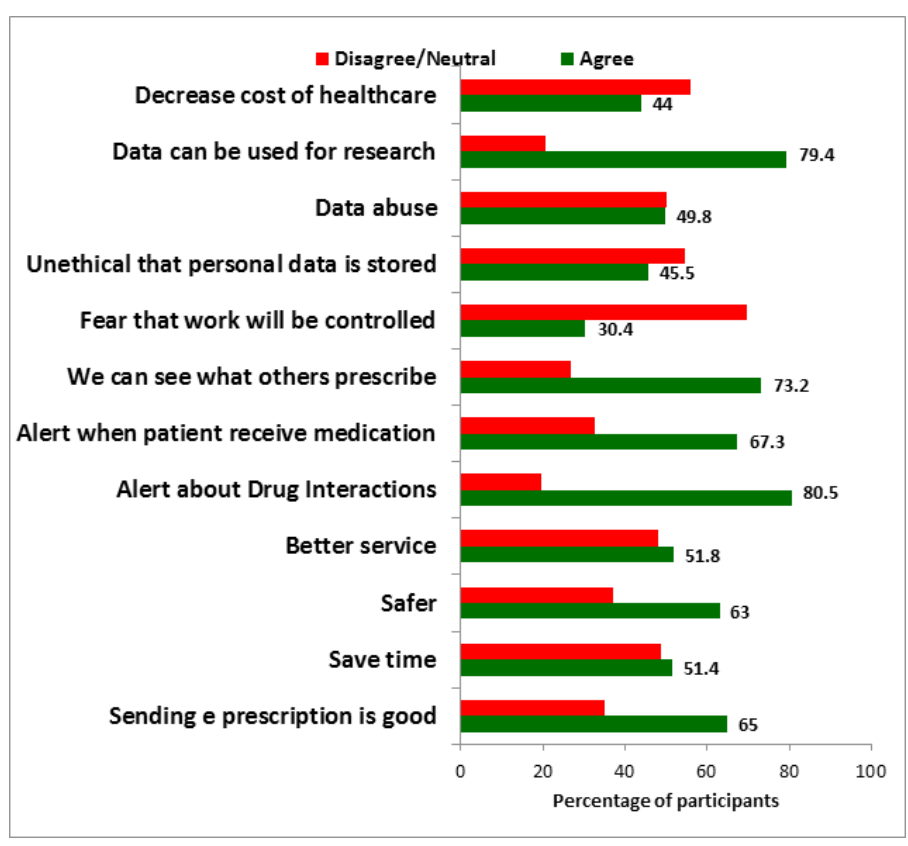

Figure 1: Perceived usefulness of e prescriptions.

complicated $(32.7 \%)$ or it would be difficult to change e-prescription (42.8\%), $77.8 \%$ thought it was easier to renew prescriptions electronically. However, $82.9 \%$ doctors claimed that they would like to meet the patients in person than give automatic refills. Only a small minority thought that e-prescriptions would improve the patient satisfaction. $79.4 \%$ opined that the pharmacies need to be well equipped to fit into the e-prescribing network. More than fifty percentage thought that e-prescribing would help in detecting medication misuse and diversion. 


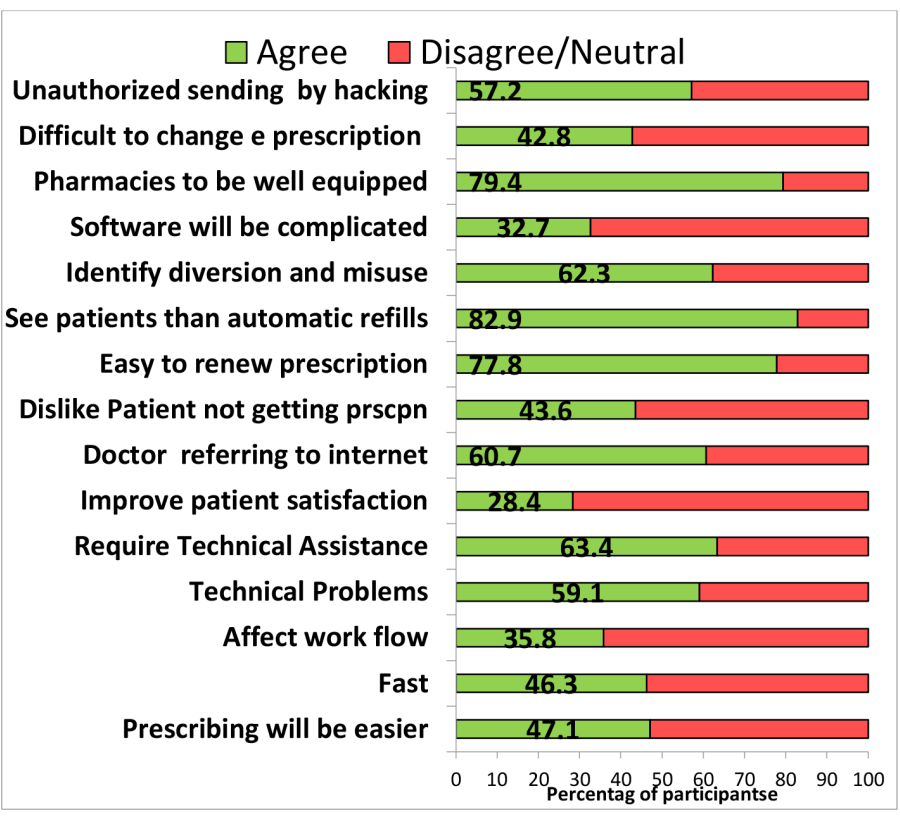

Figure 2: Perceived ease of use of e prescriptions.

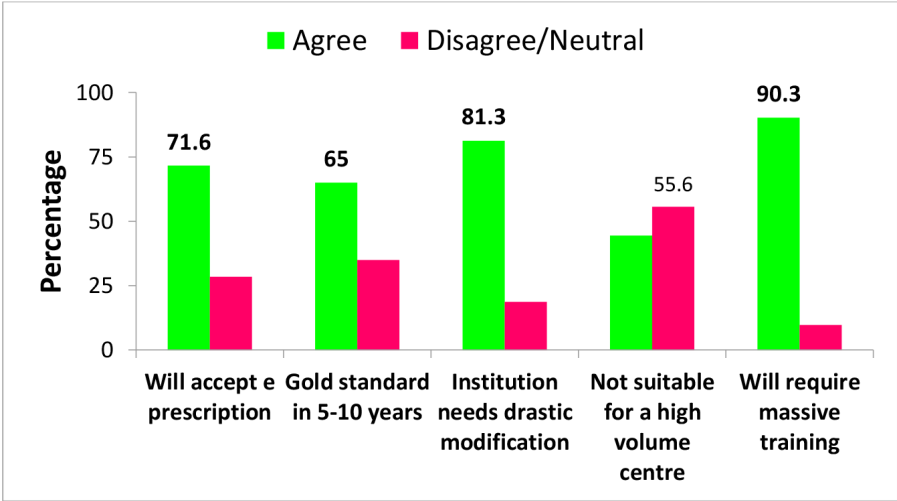

Figure 3: Perceived fitness of e prescription.

Figure 3 depicts the perceived fitness of e-prescription in the institution. Even though majority of the participants agreed to accept e-prescription once it was adopted in the institution, $55.6 \%$ felt that it was not suitable for a high volume centre like ours. There was a compelling demand for infrastructure development and massive training in the Institution. Almost two third of the participants felt that e-prescribing would be the gold standard in next five to ten years in India.

Table 3 summarises the factors associated with perceived usefulness, ease of use and fitness of e-prescription after performing univariate analysis. Binary logistic regression was performed with significant factors of univariate analysis as summarized in Table 4. Good computer knowledge and dislike for paper prescriptions were found to be predictors of positive attitude to usefulness of e-prescription. Knowledge about e-prescription and dislike for paper prescriptions were positive predictors of perceived ease of use and fitness of e-prescription.

\section{DISCUSSION}

Electronic prescription is a long overdue alternative to the five thousand year old prescription using pen and paper. About three billion paper prescriptions are written every year in India. ${ }^{13}$ Electronic prescribing and
Table 3: Univariate analysis of factors associated with perceived usefulness, ease of use and fitness of e prescription.

\begin{tabular}{|c|c|c|c|c|}
\hline Factors & $\mathrm{Chi}^{2}$ & $p$ value & $\begin{array}{l}\text { Odds } \\
\text { Ratio }\end{array}$ & $\begin{array}{c}\text { 95\% Confidence } \\
\text { Interval }\end{array}$ \\
\hline \multicolumn{5}{|c|}{ Perceived Usefulness } \\
\hline Medical specialty & 3.8 & 0.05 & 2.58 & $1.1-6.9$ \\
\hline $\begin{array}{l}\text { Good computer } \\
\text { Knowledge }\end{array}$ & 18.9 & $<0.001$ & 4.7 & $2.2-9.9$ \\
\hline $\begin{array}{l}\text { Computer use in } \\
\text { hospital }\end{array}$ & 5.2 & 0.022 & 2.79 & $1.1-6.9$ \\
\hline $\begin{array}{l}\text { Comfort with } \\
\text { computer use }\end{array}$ & 10.7 & 0.001 & 3.2 & $1.5-6.6$ \\
\hline $\begin{array}{l}\text { Dislike paper } \\
\text { prescriptions }\end{array}$ & 6.2 & 0.013 & 2.64 & $1.2-5.8$ \\
\hline $\begin{array}{l}\text { Knowledge of e } \\
\text { prescription }\end{array}$ & 4.8 & 0.028 & 2.13 & $1.1-4.2$ \\
\hline \multicolumn{5}{|c|}{ Perceived Ease of use } \\
\hline $\begin{array}{l}\text { Comfort with } \\
\text { computer use }\end{array}$ & 4.9 & 0.027 & 2.09 & $1.1-4.0$ \\
\hline $\begin{array}{l}>5 \text { years Work } \\
\text { Experience }\end{array}$ & 4.4 & 0.036 & 1.79 & $1.0-3.1$ \\
\hline $\begin{array}{l}\text { Knowledge of e } \\
\text { prescription }\end{array}$ & 5.2 & 0.023 & 1.91 & $1.1-3.4$ \\
\hline Send e prescription & 5.1 & 0.023 & 2.24 & $1.1-4.6$ \\
\hline $\begin{array}{l}\text { Dislike paper } \\
\text { prescriptions }\end{array}$ & 4.5 & 0.035 & 1.72 & $1.1-2.9$ \\
\hline \multicolumn{5}{|c|}{ Perceived fitness } \\
\hline Medical Specialty & 4.9 & 0.026 & 2.18 & $1.1-4.4$ \\
\hline $\begin{array}{c}\text { Computer use in } \\
\text { hospital }\end{array}$ & 3.9 & 0.05 & 1.8 & $1.1-3.4$ \\
\hline $\begin{array}{l}\text { Dislike paper } \\
\text { prescriptions }\end{array}$ & 9.4 & 0.013 & 2.46 & $1.4-4.4$ \\
\hline $\begin{array}{l}\text { Knowledge of e } \\
\text { prescription }\end{array}$ & 8.2 & 0.004 & 2.25 & $1.3-4.0$ \\
\hline
\end{tabular}

Table 4: Positive predictors of usefulness, ease of use and fitness of e prescription by binary logistic regression.

\begin{tabular}{ccccc}
\hline $\begin{array}{c}\text { Independent } \\
\text { predictors }\end{array}$ & Wald & $\begin{array}{c}p \\
\mathbf{p} \\
\text { value }\end{array}$ & $\begin{array}{c}\text { Adjusted Odds } \\
\text { Ratio }\end{array}$ & $\begin{array}{c}\text { Confidence } \\
\text { Interval }\end{array}$ \\
\hline $\begin{array}{c}\text { Perceived usefulness } \\
\text { Good computer } \\
\text { knowledge }\end{array}$ & 16.6 & 0.001 & 4.79 & $2.3-10.1$ \\
$\begin{array}{c}\text { Dislike for paper } \\
\text { prescription }\end{array}$ & 5.73 & 0.017 & 2.69 & $1.2-6.1$ \\
& Perceived ease of use & \\
$\begin{array}{c}\text { Knowledge of e } \\
\text { prescription }\end{array}$ & 5.38 & 0.02 & 1.97 & $1.1-3.5$ \\
$\begin{array}{c}\text { Dislike paper } \\
\text { prescriptions }\end{array}$ & 4.7 & 0.03 & 1.77 & $1.1-2.9$ \\
$\begin{array}{c}\text { Knowledge of e } \\
\text { prescription }\end{array}$ & 8.62 & 0.003 & 2.38 & $1.3-4.3$ \\
$\begin{array}{c}\text { Dislike paper } \\
\text { prescriptions }\end{array}$ & 9.68 & 0.002 & 2.59 & $1.4-4.7$ \\
\hline
\end{tabular}


dispensing processes of drugs whether in medical practice, follow up or research has become an integral part of pharmacoinformatics. ${ }^{14}$ Studies on barriers and facilitators to implementation of electronic prescription have been done amongst physicians, pharmacists, staff of physicians as well as IT staff. ${ }^{15}$ This study was done amongst the prescribing doctors of a rural tertiary care institution with more than $50 \%$ of participants taking care of high patient load.

Incentivizing electronic prescribers, data on reduction in prescription errors and its impact on health outcomes, online real time verifications by pharmacists, formulary adherence, reduction in adverse drug reactions and timely drug-drug interaction alerts have paved to the slow but successful adoption of e-prescribing in the developed nations. ${ }^{16}$ Technology acceptance model (TAM) research among physicians have revealed contrasting results between the pre and post implementation phases. ${ }^{17-18}$

A study done in the pre-implementation phase of primary care centres revealed that the median perceived usefulness and ease of use were respectively 4.1 and 3.2 in one centre and it was 4.2 and 3.5 in another. ${ }^{19}$ This is comparable to our study where the mean perceived usefulness and ease of use was $3.5 \pm 0.47$ and $3.35 \pm 0.49$ respectively. Around $71.6 \%$ opined that they were willing to adopt e-prescribing in the future and $65 \%$ felt that it would be the gold standard for prescribing in the coming years. There was a demand for infrastructure development, computer skills training as well as development of drug equipped internal pharmacies which can meet the demands of prescriptions generated electronically.

Electronic health records (EHR) have existed in the developed nations since 1970 s. ${ }^{20}$ Early adoption have slowed and soured because of resistance to accept computerised protocols and clinical information systems. ${ }^{16}$ A review by Jeetu and Girish found that e-prescriptions were less variable and generated mostly default medication instructions with signatured messages, which automatically appear within the text box in the EHR. ${ }^{21}$ By providing flexibility through doctor directed prescribing, provision of personal digital assistants with preferred drugs/personal drugs ( $\mathrm{P}$ drugs) has paved way to acceptance of e-prescribing. ${ }^{16}$

Dislike for paper prescriptions was the single common factor associated with participants positive attitude towards perceived usefulness, ease of use and fitness to adopt technology in this institution. Prescribing errors in terms of medication, direction, length of treatment, dose, dosage form, amount to be dispensed, poor legibility and use of inappropriate abbreviations are one of the largest preventable errors in the hospitals. ${ }^{2,16}$ Kaushal et al. found that e-prescribing adopters had significantly lower rates of prescribing errors (6.6 versus 38.4) and near misses (1.3 versus 2.7) than non-adopters at one year. ${ }^{2}$ Yugandhar et al. opined that electronic prescribing system reduced $75 \%$ of prescribing errors with error rate being $8.4 \%$ compared to $33 \%$ of handwritten prescriptions. ${ }^{22}$ The dispensing errors due to inadequate deciphering of "doctor scribble" can be eliminated. Handwritten prescriptions had 5.5 higher odds of having prescribing errors (OR 5.5, 95\% CI 4.6-6.1). ${ }^{22}$ Panchbhai et al. stated that pre-printed prescriptions and electronic entry devices can reduce illegibility and hence medication errors. ${ }^{23}$ The drug-drug interaction alerts, knowledge about past history of drug allergies and adverse drug reactions, suggestion of right dosage will make e-prescriptions prone for less prescribing errors. Patients have picked up and taken drugs with perseverance with e-prescriptions than those with paper prescriptions leading to better compliance. ${ }^{16}$

Good computer knowledge was found to be predictors of positive attitude towards usefulness of e-prescription. Electronic prescribing system is a complex system necessitating finesse in operating computers or digital assistants who are experts. Physicians require additional training in utilizing e-prescribing technology efficiently and effectively. To facilitate the usefulness of e-prescriptions the software must be user friendly, easily operable, customized and updated in terms of local requirements and prescribing trends. A predefined notion that use of technology is expensive, hard to learn, time consuming and error prone is a major barrier in adoption of computerized prescriptions. The positive influence of previous computer knowledge has been demonstrated in previous studies. ${ }^{17,24}$ Previous knowledge about e-prescriptions was associated with perceived ease of use and perceived fitness of e-prescription in this institution. Even with previous knowledge and hands on experience many e-prescribers have quit the same owing to technical problems with network connectivity, lack of patient identifiers, time pressure, uncertainty on receipt, processing and dispensing of drugs for e-prescriptions from pharmacies. ${ }^{25}$ Lack of incentives, suspicion on encroachment of professional autonomy by higher authorities, loss of patient's privacy by hacking, stealing computers or access to database are other concerns which can demotivate the prescribers in using e-prescriptions. This research summarizes the perceptions of prescribers in pre-implementation period of a single tertiary care institution. Even though the study population corresponds to usual proportion of prescribers in the institution a larger sample size would have yielded better results.

\section{CONCLUSION}

Electronic prescribing is a long term investment to reap benefits in terms of ensuring patient safety, increasing quality healthcare and tuning hospitals in right stride towards "Digital India". Dislike for paper prescriptions was the single most important factor associated with perceived usefulness, perceived ease of use and perceived fitness of e-prescription in the institution. Dislike for paper prescriptions by educating the prescribers on preventable medication errors associated with it can lead to the acceptance of e-prescribing. There needs to be extensive training of stakeholders especially prescribers and infrastructure development before its adoption to make it successful and fruitful.

\section{ACKNOWLEDGEMENT}

We acknowledge the participants of the study who completed the questionnaire despite the busy schedule. We thank State Board of Medical Research, Government of Kerala for funding this study.

\section{CONFLICT OF INTEREST}

The authors declare no conflict of interest.

\section{ABBREVIATIONS}

CI: Confidence Interval; EHR: Electronic Health Record; e-prescription: Electronic prescription; e-prescribing: Electronic prescribing; IT: information technology, OR: Odds ratio; P drugs: Personal drugs; prscpn: Prescription; SPSS: Statistical Package for Social Sciences; TAM: Technology Acceptance Model

\section{SUMMARY}

Electronic prescriptions are computerised prescriptions.This study aimed at determining the perceptions of prescribing doctors of a tertiary care centre about electronic prescription in three domains namely perceived usefulness, perceived ease of use and fitness of institution for the adoption of e- prescribing system .Dislike for paper prescription was found to be the most important factor associated with the three domains. Proper training of faculty in information technology with infrastructure development will envisage e-prescriptions as the gold standard for prescribing in India in the coming years.

\section{REFERENCES}

1. Velo GP, Minuz P. Medication errors: Prescribing faults and prescription errors. 
Br J Clin Pharmacol. 2009;67(6):624-8.

2. Kaushal R, Kern LM, Barron Y, Quaresimo J, Abramson EL. Electronic prescribing improves medication safety in community-based office practices. J Gen Intern Med. 2010;25(6):530-6.

3. Miller SR. Scrip for success. Kentucky family practice uses electronic prescriptions to improve efficiency, revenue and customer service. Health Manag Technol. 2003;24(10):20-1.

4. Thomas CP, Kim M, McDonald A, Kreiner P, Kelleher SJ, Blackman MB, et al. Prescriber's expectations and barriers to electronic prescribing of controlled substances. J Am Med Inform Assoc. 2012;19(3):375-81.

5. Nebeker JR, Hoffman JM, Weir CR, Bennett CL, Hurdle JF. High rates of adverse events in a highly computerized hospital. Arch Intern Med. 2005;165(10):1111-6.

6. Odukoya OK, Stone JA, Chui MA. E-prescribing errors in community pharmacies: Exploring consequences and contributing factors. Int J Med Inform. 2014;83(6):427-37.

7. E health Project-A Synopsis. 2018. Available at http://arogyakeralam.gov.in/ index.php/ehealth.

8. Agency for Healthcare Research and Quality. A Toolset for E-Prescribing Implementation in Independent Pharmacies. 2011. [Cited on April 11 2018]. Available at: https://healthit.ahrq.gov/sites/default/files/docs/page/AHRQ-RAND PharmacyToolset.pdf

9. Cork RD, Detmer WM, Friedman CP. Development and Initial Validation of an Instrument to Measure Physicians' Use of, Knowledge about, and Attitudes toward Computers. J Am Med Inform Assoc. 1998;5(2):164-76.

10. Rogers EM. Attributes of innovation and their rate of adoption. In: Diffusion of Innovations. $4^{\text {th }}$ edition. New York: The Free Press. 1995:204-51.

11. Davis FD, Bagozzi RP, Warshaw PR. User acceptance of computer technology: A comparison of two theoretical models. Management Sci. 1989;35(8):982-1003.

12. Dixon DR, Dixon BJ. Adoption of information technology enabled innovations by primary care physicians: Model and questionnaire development. Proc Annu Symp Comput Appl Med Care. 1994:631-5.

13. Medhi B, Prakash A. Electronic Prescribing. In: Advanced Pharmacology. Hyderabad, Pharma Med Press. 2014:476-82.
14. Neoh CF, Zainal IN, Hameed MA, Khan TM, Ming LC. Development and Progress of Pharmacoinformatics in Pharmaceutical and Health Sciences. J Young Pharm. 2015;7(3):155-63.

15. Gagnon MP, Nsangou ÉR, Payne-Gagnon J, Grenier S, Sicotte C. Barriers and facilitators to implementing electronic prescription: A systematic review of user groups perceptions. J Am Med Inform Assoc. 2014;21(3):535-41.

16. Salmon JW, Jiang R. E-Prescribing: History, Issues, and Potentials. Online J Public Health Inform. 2012;4(3).

17. Sicotte C, Taylor L, Tamblyn R. Predicting the use of electronic prescribing among early adopters in primary care. Can Fam Physician 2013;59(7):e312-21.

18. Green LA. Gorenflo DW, Wyszewianski L. Michigan Consortium for Family Practice Research. Validating an instrument for selecting interventions to change physician practice patterns: A Michigan Consortium for Family Practice Research Study. J Fam Pract. 2002;51(11):938-42.

19. Devine EB, Patel R, Dixon DR, Sullivan SD. Assessing attitudes towards electronic prescribing adoption in primary care: A survey of prescribers and staff. Inform Prim Care. 2010;18(3):177-87.

20. Schade CP, Sullivan FM, De Lusignan S, Madeley J. E-Prescribing, Efficiency, Quality: Lessons from the Computerization of UK Family Practice. J Am Med Inform Assoc. 2006;13(5):470-5.

21. Jeetu G, Girish T. Prescription drug labelling medication errors: a big deal for pharmacists. J Young Pharm. 2010;2(1):107-11.

22. Yugandher B, Shewade DG, Dharanipragada K, Batmanabane G. Impact of Electronic Prescribing System on Prescribing Error Rate at Patients' Transition of Care: An Interventional Study. J Young Pharm. 2017;9(3):441-5.

23. Panchbhai AS. Rationality of Prescription Writing. Ind J Pharmaceu Edn Res. 2013;47(4):7-15

24. Taylor S, Todd P. Assessing IT usage: The role of prior experience. MIS Quarterly 1995; 19(4):561-70

25. Wang CJ, Patel MH, Schueth AJ, Bradley M, Wu S, Crosson JC, et al Perceptions of standards-based electronic prescribing systems as implemented in outpatient primary care: A physician survey. J Am Med Inform Assoc. 2009;16(4):493-502

Article History: Submission Date : 03-04-2018; Revised Date : 14-05-2018; Acceptance Date : 08-06-2018.

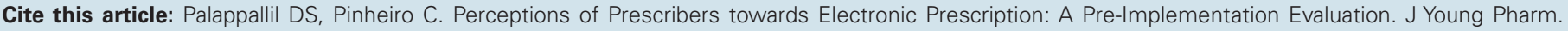
2018;10(3):313-7. 